\title{
TEXTURE DEVELOPMENT AND LENGTH CHANGES IN COPPER BARS SUBJECTED TO FREE END TORSION
}

\author{
L. S. TÓTH, ${ }^{1}$ J. J. JONAS, ${ }^{2}$ D. DANIEL ${ }^{2}$ and J. A. BAILEY ${ }^{3}$ \\ ${ }^{1}$ Institute for General Physics, Eötvös University 1445 Budapest, P.O. Box 323, \\ Hungary \\ ${ }^{2}$ Metallurgical Engineering, McGill University 3450 University St., Montreal, \\ H3A 2 A7 Canada \\ ${ }^{3}$ Mechanical and Aerospace Engineering, North Carolina State University, \\ Raleigh, N.C. 27695 U.S.A.
}

(4 April 1992)

\begin{abstract}
Free-end torsion tests were carried out on polycrystalline copper samples at room temperature, $125^{\circ} \mathrm{C}$, $200^{\circ} \mathrm{C}$ and $300^{\circ} \mathrm{C}$. The lengths of the samples increased at room temperature and $125^{\circ} \mathrm{C}$, but increased and then decreased at $200^{\circ} \mathrm{C}$ and $300^{\circ} \mathrm{C}$. Pole figures were measured on these samples at increasing shear strains up to $\gamma=11$. ODF's were calculated from the pole figures, which enabled the texture development at the two higher temperatures to be distinguished from that observed at the two lower temperatures. Analysis of these ODF's indicates that the low temperature torsion textures are entirely attributable to dislocation glide and can be predicted by means of the conventional texture development programs of crystal plasticity. By contrast, the high temperature textures display evidence for dynamic recrystallization, the occurrence of which seems to be responsible for the shortening. Dynamic recrystallization removes the $\{100\}\langle 110\rangle$ or $\mathrm{C}$ component and strengthens the rotated cube and the $\{111\}\langle 110\rangle$ or A components.
\end{abstract}

KEY WORDS Copper bars, torsion tests, length changes, textures, orientation distribution functions, ODF's, dynamic recrystallization.

\section{INTRODUCTION}

The length changes that take place when copper rods are twisted under conditions of free axial movement have been studied by a number of researchers (Swift, 1947, Hardwick and Tegart, 1961, Stüwe and Turck, 1964, Morozumi, 1965, Bailey et al., 1972, Sekine et al., 1981). It was generally observed that there is lengthening at the initiation of straining. Shortening takes place at high strains $\left(\gamma>5\right.$, Morozumi, 1965) when the temperature is raised above $200^{\circ} \mathrm{C}$. Above $500^{\circ} \mathrm{C}$, shortening is observed almost from the beginning of twisting (Hardwick and Tegart, 1961, Morozumi, 1965). Initially $\langle 111\rangle$ textured copper wires also show shortening behavior, even at room temperature (Tóth et al., 1991a, 1991b).

These experimental studies paid little attention to the texture and to the microstructural changes taking place during straining. A comprehensive investigation in which texture variations were detected was conducted by Montheillet and co-workers $(1984,1985)$ for fixed end torsion. That work and other theoretical simulations (Gil Sevillano et al., 1975, Canova et al., 1985, Tóth and 
Jonas, 1989, Tóth et al., 1988, 1989, 1991a, 1991b, Neale et al., 1990, Harren et al., 1989) have revealed the relationship between axial effects and texture evolution.

In the present paper, experimental results are presented for the large strain shear $(2<\gamma<12)$ of copper bars twisted under free-end conditions. The experiments were conducted at four temperatures up to $300^{\circ} \mathrm{C}$. Development of the texture was followed by means of pole figures and ODF analysis. These reveal the presence of small "tilts" of the ideal components with respect to their symmetry positions, as was observed in the fixed end case (Montheillet et al., 1984, 1985). Evidence was also found for the occurrence of dynamic recrystallization at higher temperatures, which is considered to be responsible for the shortening behavior, as discussed in more detail elsewhere (Tóth et al., 1992).

\section{EXPERIMENTAL PROCEDURE}

The specimens were machined from pure copper bars $(99.95 \%)$ to a diameter of $6.4 \mathrm{~mm}$ and to two different gauge lengths: 14 and $8 \mathrm{~mm}$. This was done in order to study the constraining effect of the shoulders on the length change process. It was observed, however, that the axial strain was about the same for samples with both gauge lengths. After machining the samples, a heat treatment of $1 / 2$ hour was applied at $550^{\circ} \mathrm{C}$ in vacuum, leading to a mean grain size of about $30 \mu \mathrm{m}$.

The experiments were conducted at the North Carolina State University in a specially designed torsion machine with a linear bearing that permits length changes during straining. The machine is instrumented so that the torque, angular displacement and length change are recorded continuously during testing. A furnace with a temperature controller was also attached. Tests were performed at room temperature, 125,200 and $300^{\circ} \mathrm{C}$ in air.

The texture was examined by measuring pole figures in a Siemens texture goniometer at McGill University. The X-ray specimens were prepared as described by Sekine et al. (1981). The ODF's were calculated at the Katholieke Universiteit Leuven using the software developed by Van Houtte (1991).

\section{EXPERIMENTAL RESULTS}

\subsection{Mechanical Behaviour}

The experimental length change-shear strain curves are plotted in Figure 1a. These all show initial lengthening, but at 200 and $300^{\circ} \mathrm{C}$, shortening is observed above shear strains of 10 and 5 , respectively. At all four temperatures, there is rapid initial proportional lengthening; the rate then decreases at shears of about 2 or 3 , depending on the temperature. Above this strain, another linear stage can be seen, which is relatively short at the highest temperature $\left(300^{\circ} \mathrm{C}\right)$.

The torque/angle of twist data were converted into shear stress/shear strain curves (Figure 1b). These initially display stage III work hardening, followed by stage IV. At all temperatures, a maximum stress is attained which is followed by softening. 

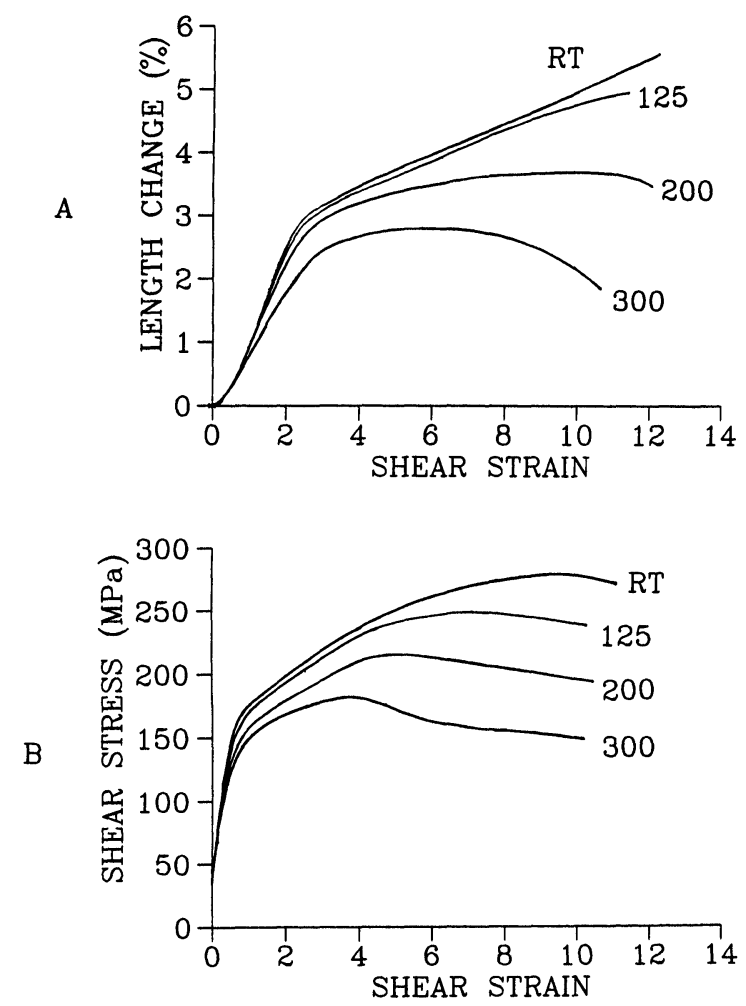

Figure 1 Length change (a) and strain hardening (b) curves for the free end torsion of copper rods. Numbers indicate the deformation temperature in ${ }^{\circ} \mathrm{C}$.

\subsection{Pole Figures}

The shear textures present just before fracture are displayed in the form of (111) pole figures in Figures $2 a-2 d$. These were recalculated from monoclinic ODF coefficients; the initial texture and the ideal components are presented in Figure 3 , and the latter are also listed in Table 1 .

The texture at room temperature (Figure 2a, $\gamma=11$ ) shows a strong B fibre $(\langle 110\rangle$ parallel to the shear direction), which is rotated in the direction of shear by about $2^{\circ}$. The $A_{1}^{*}$ part of the $A$ fibre $(\{111\}$ parallel to the axial direction) is somewhat stronger than the $A_{2}^{*}$, although the situation is opposite at low strains (see Table 2 as well as section 3.3 ODF Results below). This suggests a texture change which is characterized by the $A_{2}^{*} \rightarrow C \rightarrow A_{1}^{*}$ transition. Similar phenomena were observed by Montheillet and co-workers for the fixed end torsion of copper bars $(1984,1985)$ and predicted theoretically by Gilormini et al. (1991).

At $125^{\circ} \mathrm{C}$ (Figure $2 \mathrm{~b}, \gamma=10.5$ ), the $\{111\}$ pole figure is similar to the room temperature one. The only difference is that the maximum intensity is about $30 \%$ stronger. The texture at $200^{\circ} \mathrm{C}$ (Figure $2 \mathrm{c}, \gamma=12$ ) again resembles those obtained at the lower temperatures, but a considerable decrease in the strength of the $\mathrm{C}$ component is evident. The $\mathrm{C}$ component is weakened even more at $300^{\circ} \mathrm{C}$ (Figure 
sense of shear: -..->
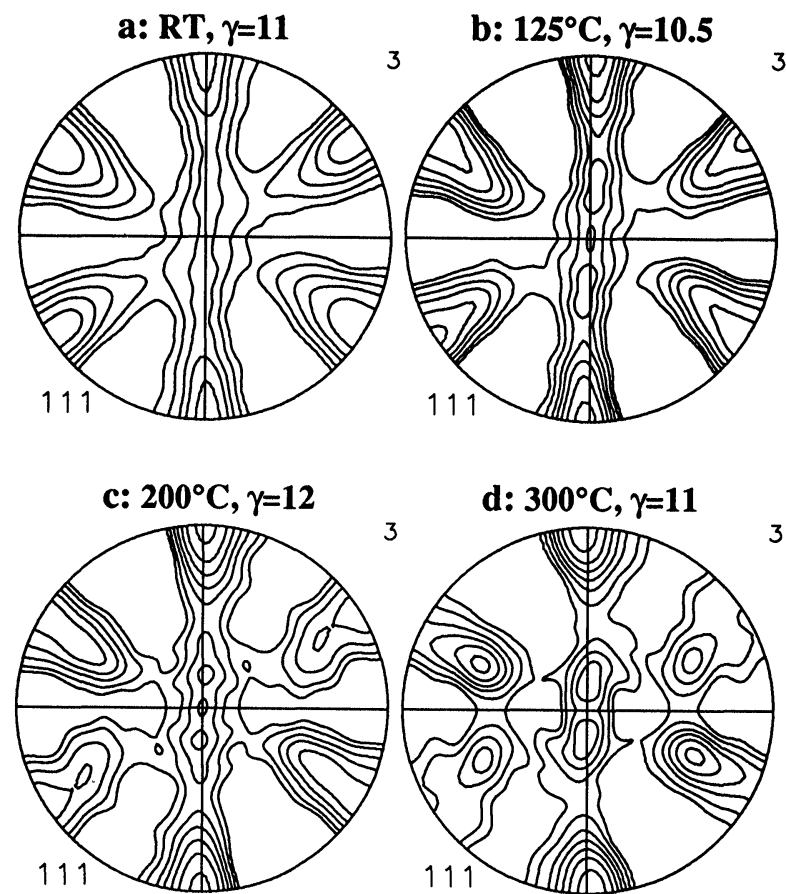

d: $300^{\circ} \mathrm{C}, \gamma=11$

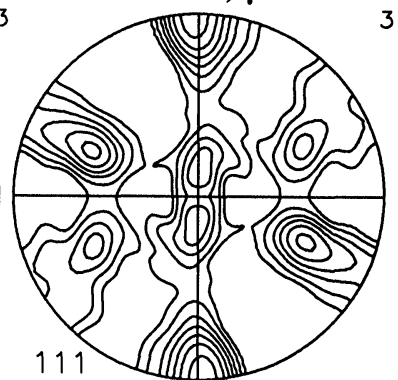

Figure $2\{111\}$ pole figures of copper rods deformed nearly to fracture. Isovalues: $0.8,1.0,1.3,1.6,2.0,2.5,3.2$.

$2 \mathrm{~d}, \gamma=11)$; this is accompanied by a decrease in the strength of the $\mathrm{A}_{2}^{*}$ orientation and a considerable intensification of the $A / \bar{A}$ component, see Table 2. Of further interest is the appearance of a rotated cube component. As can be seen from Figure $3 b$, the introduction of this component is responsible for the intensity difference between the two centro-symmetric $A / \bar{A}$ texture components in Figure 2d. This topic is considered in greater detail in the ODF section that follows.

\subsection{ODF Results}

In this section, the ODF results obtained from 10 selected samples are displayed in the form of $\Phi_{2}=$ constant sections. Although $\Phi_{2}$ intervals of $15^{\circ}$ are employed here to save space, these are sufficient to characterize the textures and identify the fibres. In order to quantify the strengths of the different ideal components and fibres, their volume fractions were computed and are displayed in Tables 2 and 3. These data were obtained by integrating the ODF's in regions bordered by a $15^{\circ}$ orientation distance from the ideal position. In this procedure, the multiplicities and distortions of Euler space were fully taken into account. In the case of ideal components separated by an orientation distance of less than $30^{\circ}$; some overlap is 


\section{a: initial texture} isovalues:

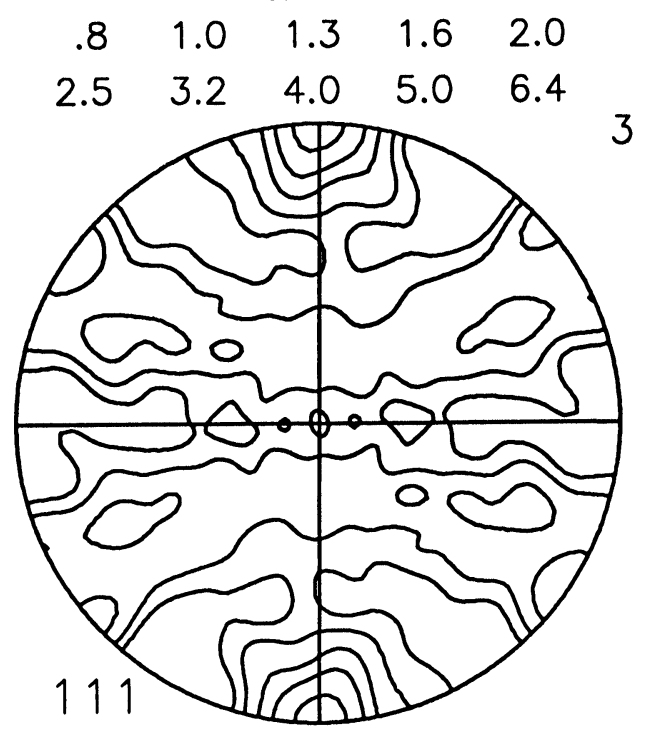

\section{b: the ideal components of shear textures}

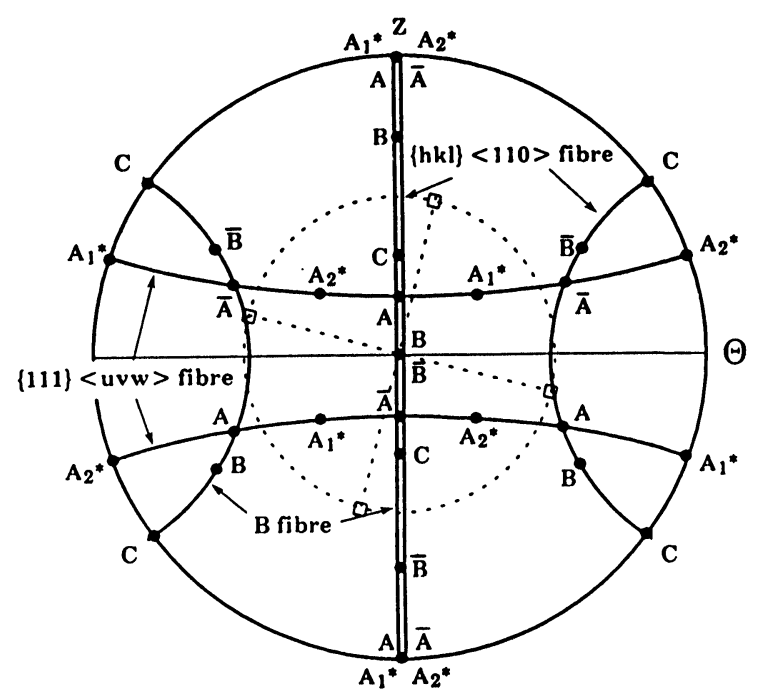

Figure 3 (a) Initial texture. (b) The ideal components of shear textures. Broken circle identifies the $\langle 001\rangle \| \mathrm{R}$ or rotated cube fibre; square symbols locate the specific $\{350\}\|\mathrm{Z},\langle 530\rangle\| \Theta$ rotated cube component observed at $200^{\circ} \mathrm{C}$ and $300^{\circ} \mathrm{C}$. 
Table 1 The ideal orientations of shear textures. (hkl): plane of shear, [uvw]: shear direction

\begin{tabular}{llllllll}
\hline & $\mathrm{A}$ & $\bar{A}$ & $B$ & $\bar{B}$ & $C$ & $A_{1}^{*}$ & $A_{2}^{*}$ \\
\hline (hkl) & $11 \overline{1}$ & $\overline{1} \overline{1} 1$ & $11 \overline{2}$ & $\overline{1} \overline{1} 2$ & 100 & $11 \overline{1}$ & $1 \overline{1} 1$ \\
[uvw] & $1 \overline{1} 0$ & $\overline{1} 10$ & $1 \overline{1} 0$ & $\overline{1} 10$ & $0 \overline{1} 1$ & $2 \overline{1} 1$ & $\overline{2} \overline{1} 1$ \\
\hline
\end{tabular}

present in the volume fractions. For example, the $A / \bar{A}$ and $B / \bar{B}$ orientations share a volume fraction of about $1.5 \%$ for this reason.

The torsion shear fibre can be divided into three sections, which are defined as follows:

B fibre; $\mathrm{C}$ to $\overline{\mathrm{B}}$ to $\overline{\mathrm{A}}$ (and symmetrically, from $\mathrm{C}$ to $\mathrm{B}$ to $\mathrm{A}$ ), common direction: (110), length: $54.73^{\circ}$;

$A_{1}$ fibre: from $\bar{A}$ to $A_{1}^{*}$ (and symmetrically, from $A_{1}^{*}$ to $A$ ), common plane: (111), length: $30^{\circ}$;

$A_{2}$ fibre; from $A$ to $A_{2}^{*}$ (and symmetrically, form $A_{2}^{*}$ to $\bar{A}$ ), common plane: (111), length: $30^{\circ}$.

The transitions between the fibres occur at the $A / \bar{A}$ ideal component (see Figure $6 \mathrm{~b})$, so that the computed volume fractions for $A / \bar{A}$ are incorporated into all three fibres (Table 3).

A further aspect of torsion textures is the "tilts" of the texture components away from their ideal or symmetrical positions (Gil Sevillano et al., 1975, Sekine et al., 1981, Montheillet et al., 1984, 1985, Toth et al., 1988, 1990). These small rotations were measured from the ODF's and are displayed in Table 4. Negative

Table 2 Volume fractions of the ideal orientations as a function of strain and temperature (ODF intensities were integrated within an orientation distance of $15^{\circ}$ ). Percentage units

\begin{tabular}{|c|c|c|c|c|c|c|}
\hline & & $A / \bar{A}$ & $B / \bar{B}$ & $C$ & $A_{1}^{*}$ & $A_{2}^{*}$ \\
\hline \multirow{2}{*}{$\begin{array}{l}\text { “Low” } \\
\text { strain }\end{array}$} & $\begin{array}{l}\text { room T } \\
(\gamma=2)\end{array}$ & 10.0 & 9.7 & 6.7 & 4.0 & 5.0 \\
\hline & $\begin{array}{l}125^{\circ} \mathrm{C} \\
(\gamma=2)\end{array}$ & 11.6 & 11.0 & 6.9 & 4.6 & 4.9 \\
\hline \multirow{3}{*}{$\begin{array}{l}\text { Medium } \\
\text { strain }\end{array}$} & $\begin{array}{l}\text { room T } \\
(\gamma=5.5)\end{array}$ & 8.1 & 11.7 & 10.8 & 3.1 & 3.0 \\
\hline & $\begin{array}{l}125^{\circ} \mathrm{C} \\
(\gamma=5.5)\end{array}$ & 9.4 & 11.8 & 9.8 & 3.3 & 3.0 \\
\hline & $\begin{array}{l}300^{\circ} \mathrm{C} \\
(\gamma=4)\end{array}$ & 14.8 & 11.3 & 3.9 & 3.9 & 3.3 \\
\hline \multirow{4}{*}{$\begin{array}{l}\text { Large } \\
\text { strain }\end{array}$} & $\begin{array}{l}\text { room T } \\
(\gamma=11)\end{array}$ & 8.2 & 11.1 & 7.0 & 4.2 & 2.4 \\
\hline & $\begin{array}{l}125^{\circ} \mathrm{C} \\
(\gamma=10.5)\end{array}$ & 12.0 & 13.4 & 8.1 & 4.7 & 3.1 \\
\hline & $\begin{array}{l}200^{\circ} \mathrm{C} \\
(\gamma=12)\end{array}$ & 13.5 & 12.2 & 5.2 & 4.2 & 3.3 \\
\hline & $\begin{array}{l}300^{\circ} \mathrm{C} \\
(\gamma=11)\end{array}$ & 16.2 & 11.6 & 3.3 & 4.0 & 3.0 \\
\hline
\end{tabular}


Table 3 Volume fractions of the ideal fibres as a function of strain and temperature (using $15^{\circ}$ spread around the fibres)

\begin{tabular}{|c|c|c|c|c|}
\hline & & $A_{1}$ fibre & $A_{2}$ fibre & B fibre \\
\hline \multirow{2}{*}{$\begin{array}{l}\text { “Low” } \\
\text { strain }\end{array}$} & $\begin{array}{l}\text { room } \mathrm{T} \\
(\gamma=2)\end{array}$ & 17.7 & 19.6 & 33.0 \\
\hline & $\begin{array}{l}125^{\circ} \mathrm{C} \\
(\gamma=2)\end{array}$ & 20.3 & 21.1 & 35.2 \\
\hline \multirow{3}{*}{$\begin{array}{l}\text { Medium } \\
\text { strain }\end{array}$} & $\begin{array}{l}\text { room T } \\
(\gamma=5.5)\end{array}$ & 14.5 & 13.5 & 39.3 \\
\hline & $\begin{array}{l}125^{\circ} \mathrm{C} \\
(\gamma=5.5)\end{array}$ & 15.9 & 15.5 & 39.5 \\
\hline & $\begin{array}{l}300^{\circ} \mathrm{C} \\
(\gamma=4)\end{array}$ & 22.9 & 22.0 & 33.2 \\
\hline \multirow{4}{*}{$\begin{array}{l}\text { Large } \\
\text { strain }\end{array}$} & $\begin{array}{l}\text { room } \mathrm{T} \\
(\gamma=11)\end{array}$ & 15.9 & 13.3 & 33.2 \\
\hline & $\begin{array}{l}125^{\circ} \mathrm{C} \\
(\gamma=10.5)\end{array}$ & 20.7 & 18.2 & 40.4 \\
\hline & $\begin{array}{l}200^{\circ} \mathrm{C} \\
(\gamma=12)\end{array}$ & 21.8 & 20.3 & 35.9 \\
\hline & $\begin{array}{l}300^{\circ} \mathrm{C} \\
(\gamma=11)\end{array}$ & 24.4 & 22.7 & 33.8 \\
\hline
\end{tabular}

Table 4 Tilts of the ideal components away from their symmetry positions with respect to the sample axis

\begin{tabular}{|c|c|c|c|c|c|c|}
\hline & & $A / \bar{A}$ & $B / \bar{B}$ & $C$ & $A_{1}^{*}$ & $A_{2}^{*}$ \\
\hline \multirow{2}{*}{$\begin{array}{l}\text { "Low" } \\
\text { strain }\end{array}$} & $\begin{array}{l}\text { room T } \\
(\gamma=2)\end{array}$ & $-2^{\circ}$ & $-2^{\circ}$ & $-3^{\circ}$ & $+1^{\circ}$ & $-6^{\circ}$ \\
\hline & $\begin{array}{l}125^{\circ} \mathrm{C} \\
(\gamma=2)\end{array}$ & $-2^{\circ}$ & $-2^{\circ}$ & $-3^{\circ}$ & $+1^{\circ}$ & $-6^{\circ}$ \\
\hline \multirow{3}{*}{$\begin{array}{l}\text { Medium } \\
\text { strain }\end{array}$} & $\begin{array}{l}\text { room T } \\
(\gamma=5.5)\end{array}$ & $-1^{\circ}$ & $-1^{\circ}$ & $-1^{\circ}$ & $+3^{\circ}$ & $-5^{\circ}$ \\
\hline & $\begin{array}{l}125^{\circ} \mathrm{C} \\
(\gamma=5.5)\end{array}$ & $-2^{\circ}$ & $-2^{\circ}$ & $-2^{\circ}$ & $+2^{\circ}$ & $-3^{\circ}$ \\
\hline & $\begin{array}{l}300^{\circ} \mathrm{C} \\
(\gamma=4)\end{array}$ & $+2^{\circ}$ & $0^{\circ}$ & $0^{\circ}$ & $+3^{\circ}$ & $-4^{\circ}$ \\
\hline \multirow{4}{*}{$\begin{array}{l}\text { Large } \\
\text { strain }\end{array}$} & $\begin{array}{l}\text { room } \mathrm{T} \\
(\gamma=11)\end{array}$ & $+2^{\circ}$ & $+1^{\circ}$ & $+2^{\circ}$ & $+4^{\circ}$ & $-3^{\circ}$ \\
\hline & $\begin{array}{l}125^{\circ} \mathrm{C} \\
(\gamma=10.5)\end{array}$ & $+1^{\circ}$ & $0^{\circ}$ & $+1^{\circ}$ & $+2^{\circ}$ & $-3^{\circ}$ \\
\hline & $\begin{array}{l}200^{\circ} \mathrm{C} \\
(\gamma=12)\end{array}$ & $+1^{\circ}$ & $+1^{\circ}$ & $+1^{\circ}$ & $+4^{\circ}$ & $-2^{\circ}$ \\
\hline & $\begin{array}{l}300^{\circ} \mathrm{C} \\
(\gamma=11)\end{array}$ & $+2^{\circ}$ & $+2^{\circ}$ & $+2^{\circ}$ & $0^{\circ}$ & $-3^{\circ}$ \\
\hline
\end{tabular}


values signify anti-shear displacements, while positive values represent shear sense tilts.

The ODF's for twisting at room temperature and at $125^{\circ} \mathrm{C}$ are presented in Figures 4 and 5, respectively. Strains of 2.0, 5.5 and $11.0\left(10.5\right.$ for $\left.125^{\circ} \mathrm{C}\right)$ have been selected to show the effect of strain on texture development. These ODF's can be interpreted with the aid of the original texture (Figure 6a) and the key to the ideal orientations (Figure 6b). It can be seen from Figure $6 a$ that the initial texture is fairly strong. The sharpest orientations are the $A_{1}^{*}, A_{2}^{*}$ and the $A / \bar{A}$ torsion components, which are part of the $\langle 111\rangle$ tensile fibre produced when the copper bars were drawn. Another component, a rotated cube, is also fairly strong. It appears along the $\Phi=0^{\circ}$ axis at several positions in each section (e.g. at $\Phi_{1}=10^{\circ}, \Phi_{1}=80^{\circ}, \Phi_{1}=100^{\circ}$ and $\Phi_{1}=170^{\circ}$ in the $\Phi_{2}=0^{\circ}$ section).

The rotated cube component also appears in all the ODF's displayed in Figures 4-7. It can be verified that at room temperature (Figure 4) and at $125^{\circ} \mathrm{C}$ (Figure 5 ), it originates from the initial texture by simple lattice rotation. As predicted by Tóth and Jonas (1989) and Gilormini et al. (1990), orientations along the $\Phi=0^{\circ}$ axis $(<100>\| R)$ are displaced by rigid body rotation during torsion; these displacements are given by $\Delta \Phi_{1}=-\Delta \gamma / 4 \pi$ (radians). The locations predicted for the rotated cube by this relation coincide fairly well with the observations in Figures 4 and 5. These components are therefore pure deformation components. By applying the same principles to the rotated cube components for the higher temperature cases (Figure 7), however, the predicted locations do not coincide with the observations. As discussed in more detail in Section 4, these components were probably introduced by the occurrence of dynamic recrystallization.

Deformation leads to the intensification of the $C$ component $\{100\}\langle 110\rangle$ and to the appearance of the $\mathrm{B} / \overline{\mathrm{B}}$ component $(\{112\}\langle 110\rangle)$. A continuous fibre develops that can be described as $\mathrm{A}_{1}^{*}, \overline{\mathrm{A}}, \overline{\mathrm{B}}, \mathrm{C}, \mathrm{B}, \mathrm{A}, \mathrm{A}_{2}^{*}$, see Figure $6 \mathrm{~b}$ (Tóth et $a l ., 1988)$. As the strain is increased from 2 to 5.5 to 11.0 , the principal change noted is the gradual weakening of the $A_{1}^{*}($ at $\gamma=5.5)$ and of the $A_{2}^{*}($ at $\gamma=11$ ). This has been explained by Gilormini and co-workers (1991) as being due to the successive lattice rotations of $A_{1}^{*}$ into $A_{2}^{*}, A_{2}^{*}$ into $C$, and then $C$ into $A_{1}^{*}$. The $125^{\circ} \mathrm{C}$ ODF (Figure 5) has the same general features as the previous one.

The influence of increasing the temperature can be seen to much greater effect in Figure 7. The fibre texture described above and attributable to deformation glide (Tóth et al., 1988, 1989, 1990, Harren et al., 1989) is still evident (see Figure $7 \mathrm{~b}$ for $\gamma=4$ at $300^{\circ} \mathrm{C}$ ); however, several new components have appeared which are not part of the deformation fibre. One example is the rotated cube component $(\{350\}\langle 530\rangle)$ due to dynamic recrystallization, which can be seen at several locations along the top of each $\Phi_{2}=$ constant section.

\section{DISCUSSION}

The lengthening behavior at low strains has been discussed and explained in some detail by numerous workers (Gil Sevillano et al., 1975, Harren et al., 1989, Tóth and Jonas, 1989, Tóth et al., 1990). It is related to the formation of textures in which the ideal components have anti-shear tilts. The reason for the asymmetry is the presence of a common orientation flow. This is a rotation around the radial 


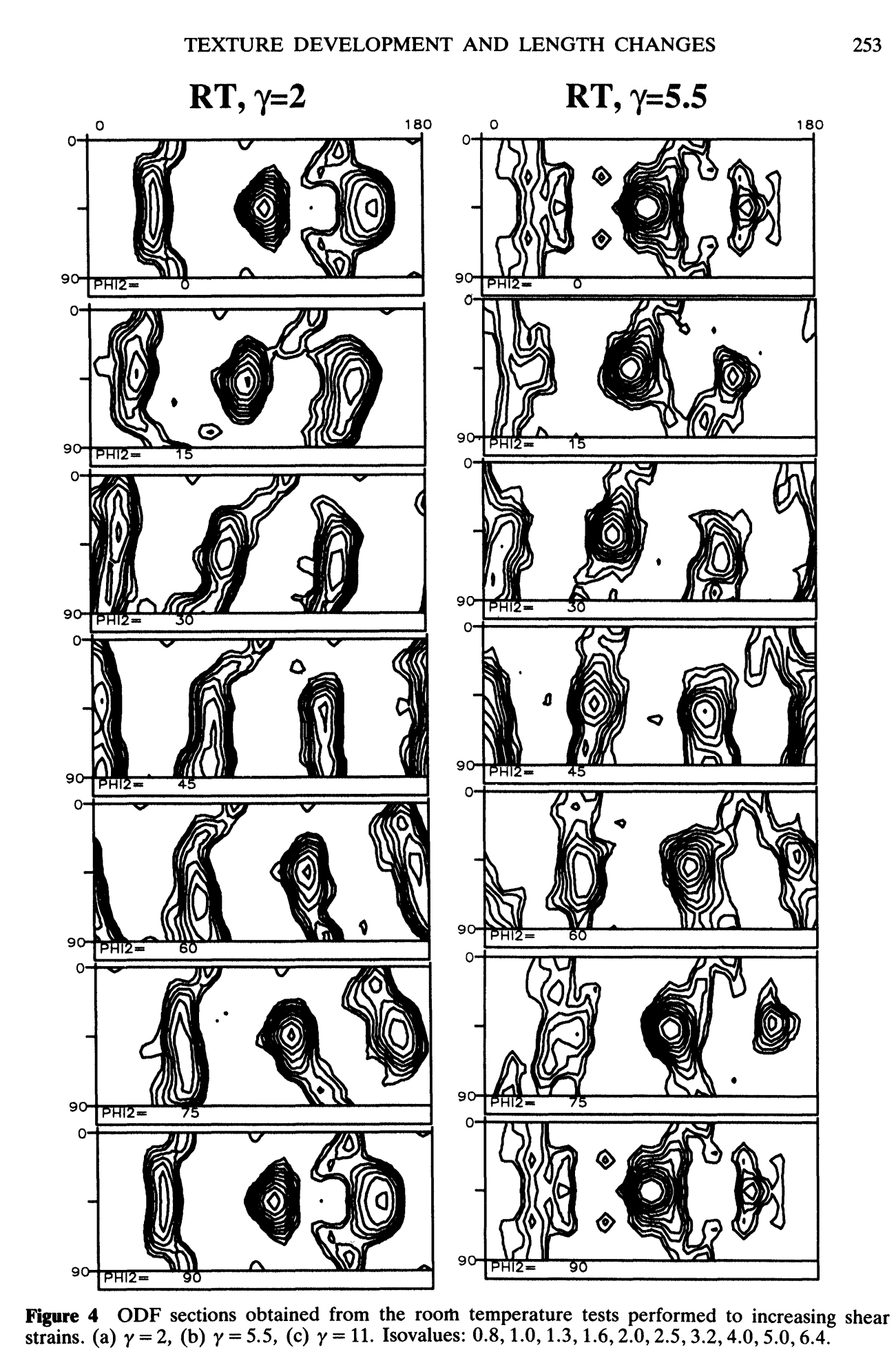




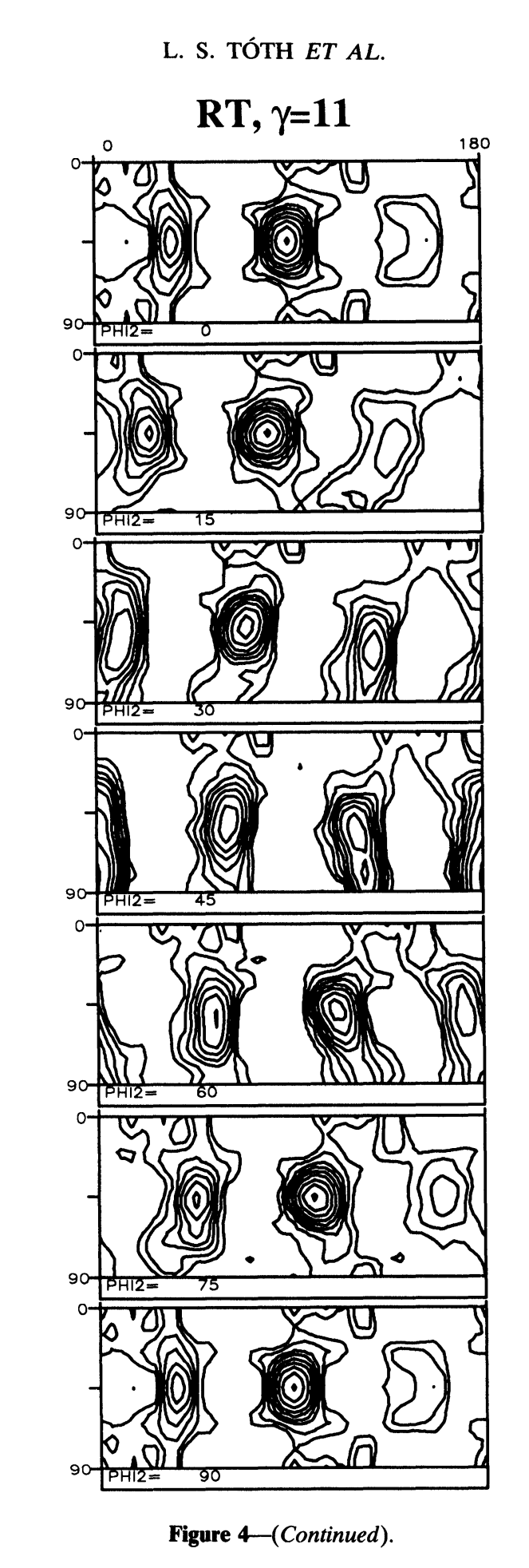


$125^{\circ} \mathrm{C}, \gamma=2$
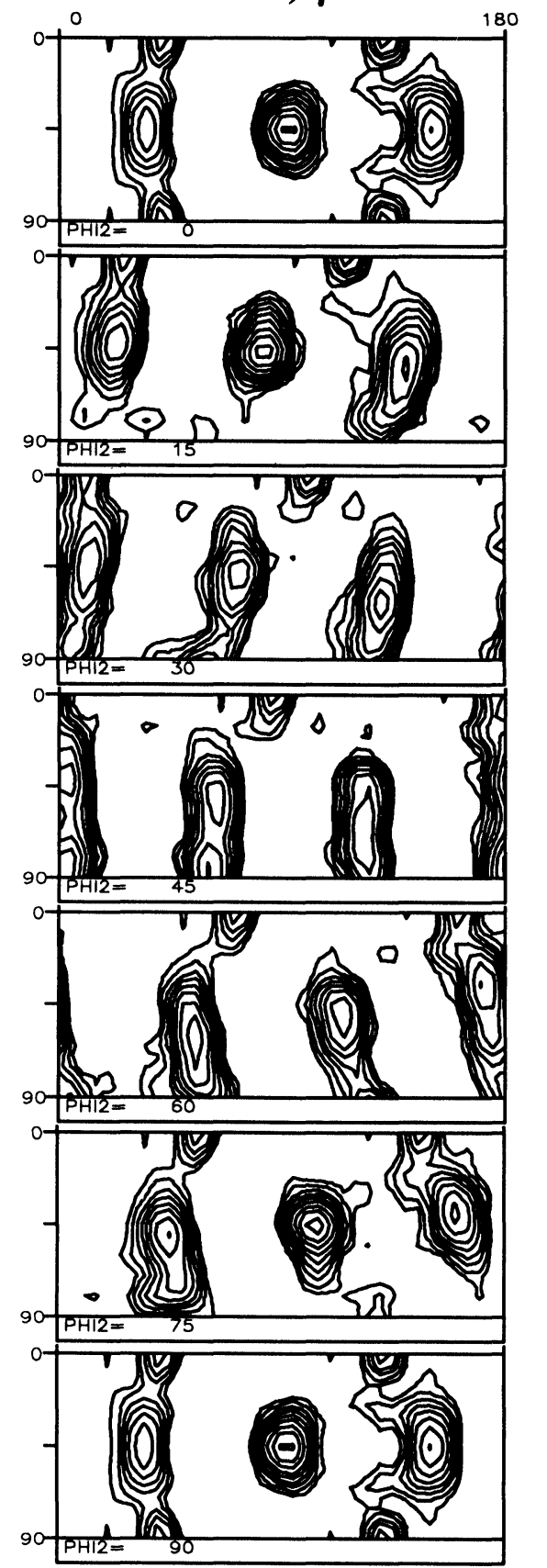

$125^{\circ} \mathrm{C}, \gamma=5.5$
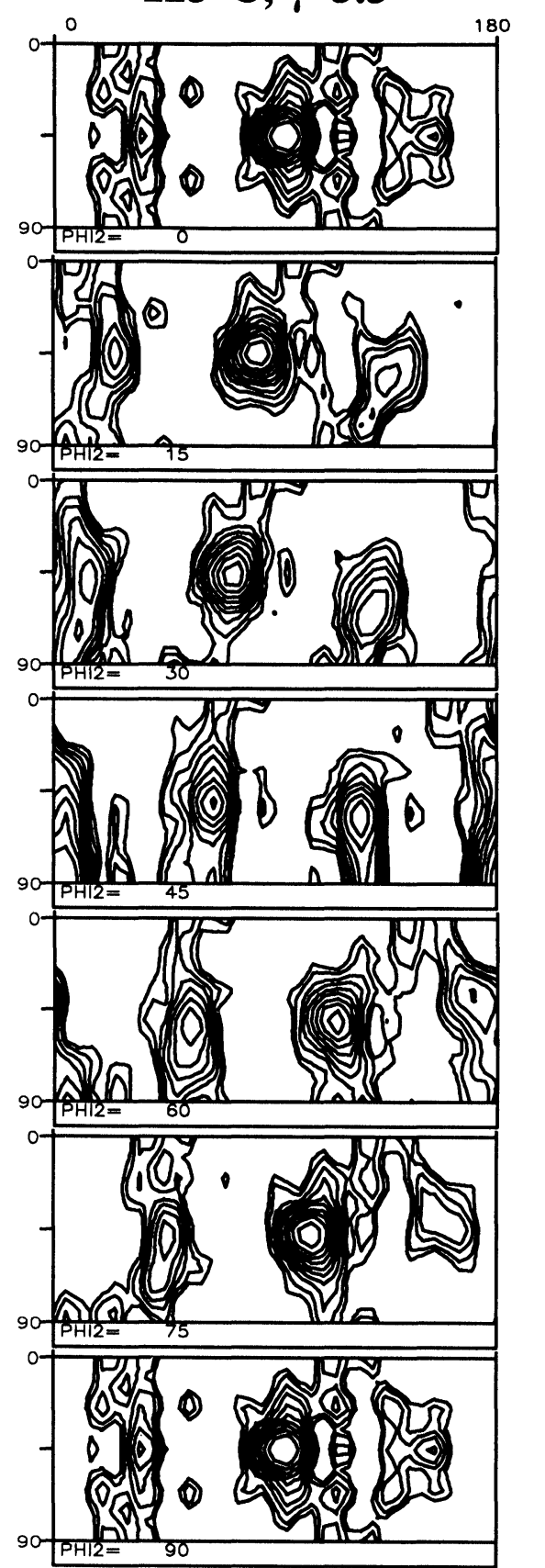

Figure 5 ODF sections obtained from the $125^{\circ} \mathrm{C}$ tests carried out to increasing shear strains. (a) $\gamma=2$, (b) $\gamma=5.5$, (c) $\gamma=10.5$. Isovalues: $0.8,1.0,1.3,1.6,2.0,2.5,3.2,4.0,5.0,6.4$. 


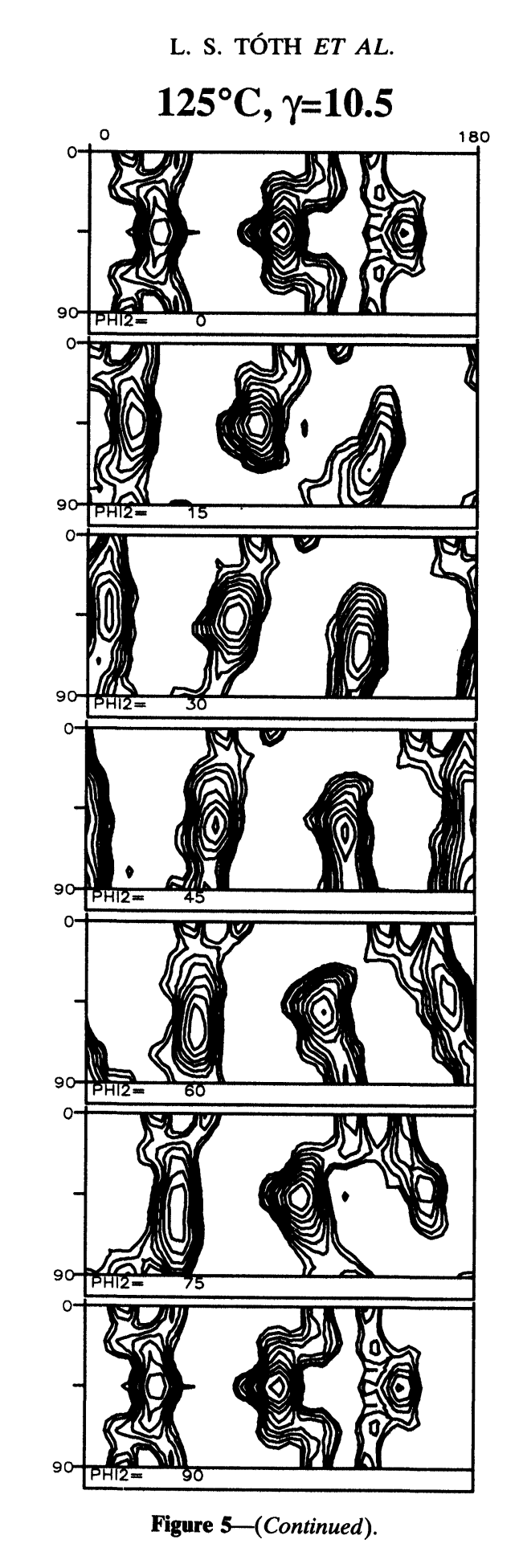


Initial texture

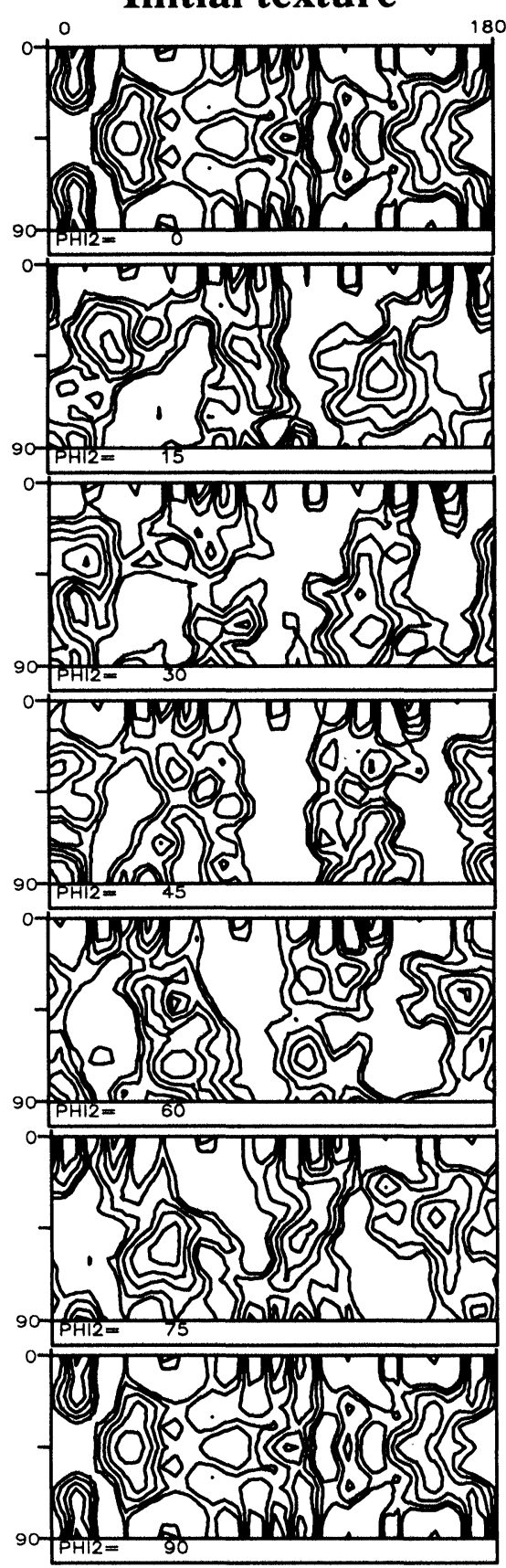

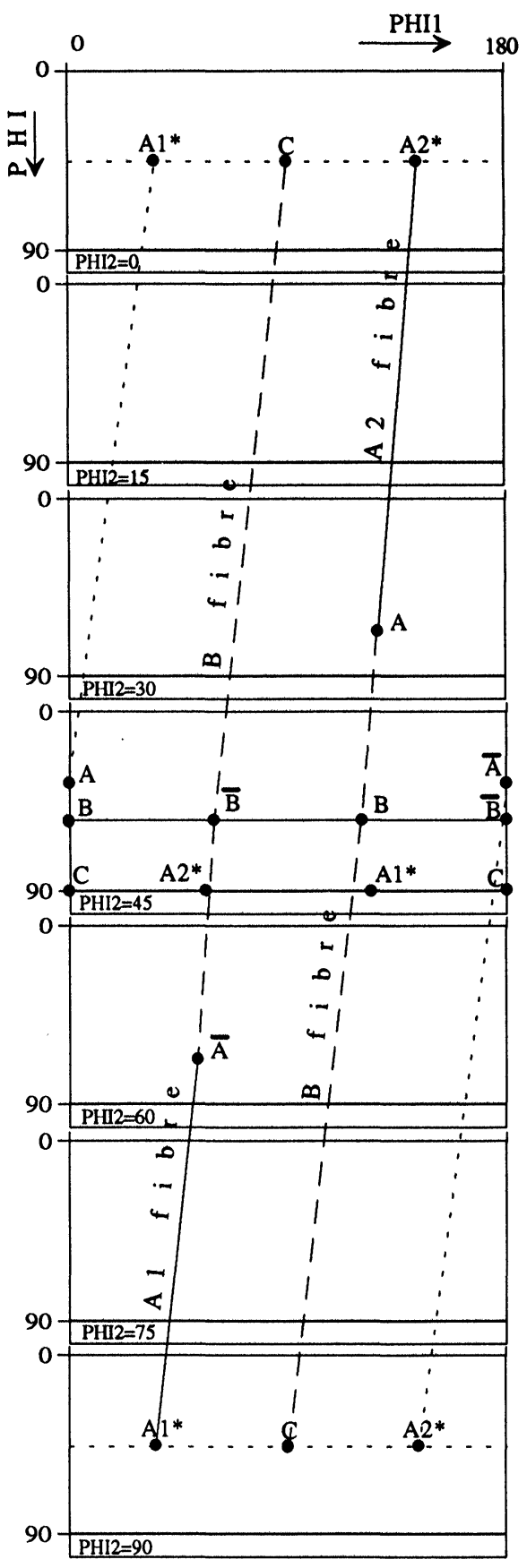

Figure 6 (a) ODF of the initial texture. Isovalues: $0.8,1.0,1.3,1.6,2.0,2.5,3.2,4.0,5.0,6.4$. (b) Positions of the ideal components and locations of the three fibres in the ODF sections. 

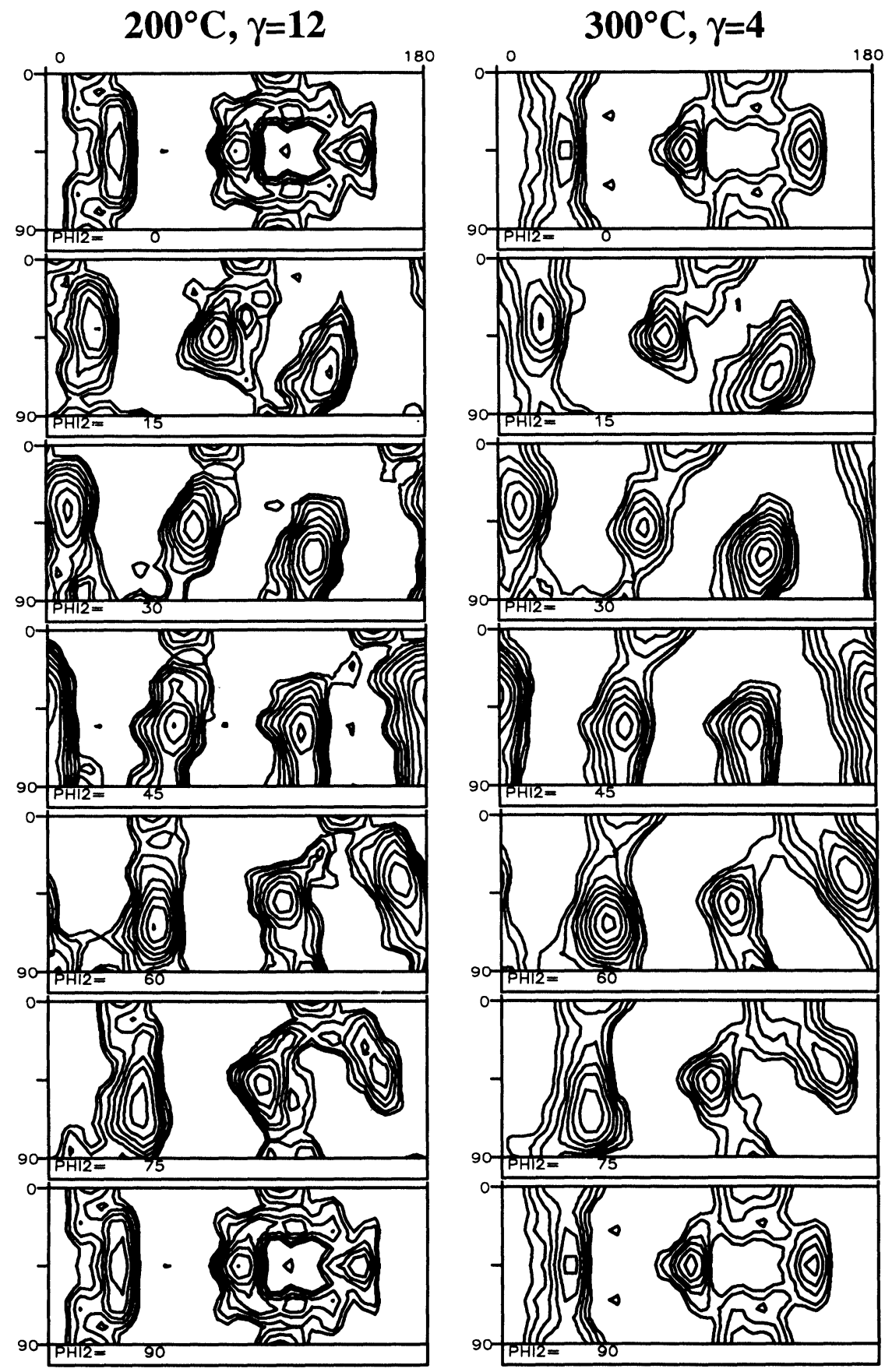

Figure 7 Typical elevated temperature textures, measured at (a) $200^{\circ} \mathrm{C}, \gamma=12$, (b) $300^{\circ} \mathrm{C}, \gamma=4$ and (c) $300^{\circ} \mathrm{C}, \gamma=11$. Isovalues: $0.8,1.0,1.3,1.6,2.0,2.5,3.2,4.0,5.0,6.4$. 
$300^{\circ} \mathrm{C}, \gamma=11$

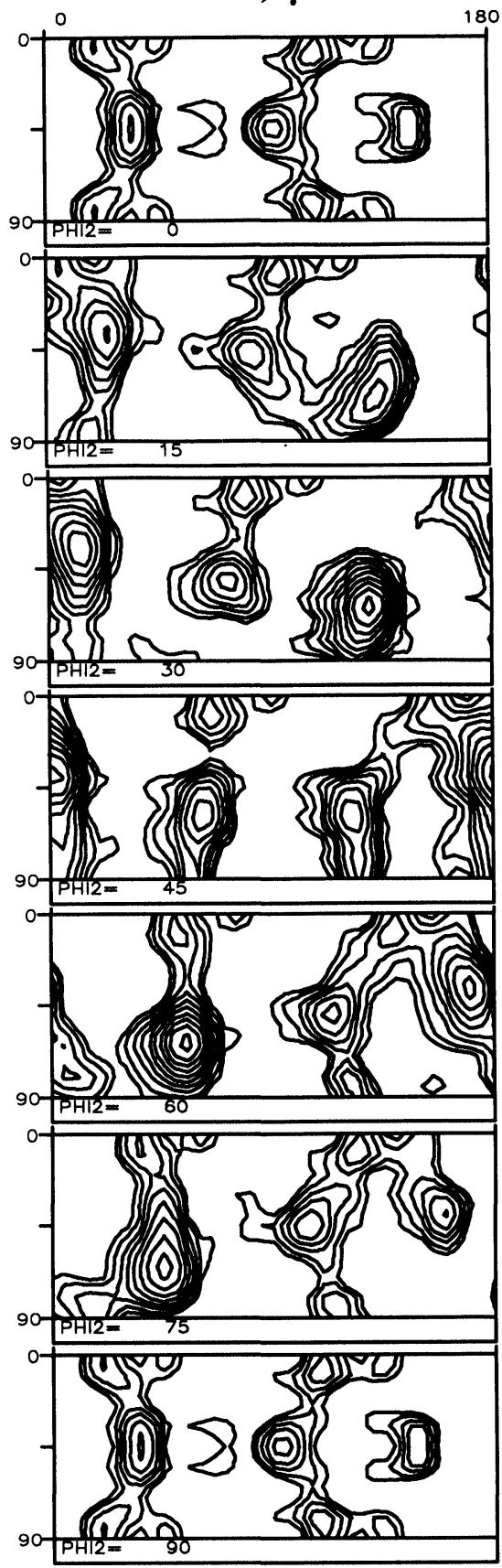

Figure 7-(Continued). 
axis of the specimen in the sense of the applied shear (Tóth et al., 1988, 1990). During the initial formation of the texture, a relatively large length increase takes place up to shears of $\gamma=2-3$ (first linear stage in Figure 1a). The rate of length change slows down once the texture is well formed as most of the grains attain orientations close to their ideal positions. Thus the amount of asymmetry and the rate of length change decrease concurrently (second linear stage in Figure 1a).

The tilts of the $A / \bar{A}, B / \bar{B}$ and $C$ components are all shear opposite below strains of 4-5 (Table 3) and shear parallel at larger strains. As indicated above, this is attributable to the characteristics of the rotation field (see Tóth et al., 1988, 1990). The $A_{1}^{*}$ and $A_{2}^{*}$ components seem to behave differently, however, as the $A_{1}^{*}$ only displays positive rotations, while the $A_{2}^{*}$ is always tilted in the sense opposite to the shear.

This apparent anomaly is a consequence of the free-end conditions of the test. As shown by Tóth et al. (1990), the ideal positions of the $\mathrm{A}_{1}^{*}$ and $\mathrm{A}_{2}^{*}$ components during free-end torsion differ from those displayed during fixed -end testing. In particular, the $A_{1}^{*}$ ideal orientation is rotated in the sense of the shear, while the $\mathrm{A}_{2}^{*}$ component is shifted in the sense opposite to the shear. As these two ideal components are closely identified with shortening and lengthening, they were labelled $\mathrm{A}_{\mathrm{S}}^{*}$ and $\mathrm{A}_{\mathrm{L}}^{*}$, respectively, in the above work.

Note that the tilts in Table 3 were measured with respect to the $A_{1}^{*}$ and $A_{2}^{*}$ ideal positions corresponding to fixed-end testing. Thus the rotations are not consistent with those of the $A / \bar{A}, B / \bar{B}$ and $C$ components, which are in the same ideal positions under both fixed-end as well as free-end conditions. Assuming the same amount of displacement for $A_{S}^{*}$ and $A_{L}^{*}$, the ideal positions of these free-end components can be estimated as: $A_{S}^{*}=\left(32.3^{\circ}, 45^{\circ}, 0\right)$ and $A_{L}^{*}=\left(147.7^{\circ}, 45^{\circ}, 0\right)$ i.e. $-3^{\circ}$ and $+3^{\circ}$ away from $A_{1}^{*}$ and $A_{2}^{*}$, respectively. With regard to these estimated locations for the $A_{S}^{*}$ and $A_{L}^{*}$ ideal components, the observed tilts of the experimental maxima are again negative for shear strains below 4-5 and positive at large strains, in harmony with the behaviours of the other components.

In order to explain the $300^{\circ} \mathrm{C}$ shortening behavior displayed in Figure 1a, several simulations of the texture development expected purely on the basis of glide considerations were carried out. The initial texture was approximated by using 800 grain orientations which were obtained from the continuous experimental ODF by a statistical type of discretization technique (Tóth and Van Houtte, 1992). For the deformation texture predictions, the rate sensitive Taylor model was employed. For the strain path, the length change curve corresponding to the $300^{\circ} \mathrm{C}$ test was prescribed and applied to the initial texture. This procedure is justified because, during free end twisting, individual elements of a given bar are not free to change their dimensions at will and the axial strain must be the same for all grains, at least on average. That is, different layers are constrained by each other in the bar. Only the boundary condition for zero axial force must be satisfied.

The result of such a simulation is plotted in $\{111\}$ pole figure form in Figure 8 for a rate sensitivity of $m=0.125$. The texture shows a small tilt in the sense of the shear and a strong $\mathrm{C}$ component. When this texture is compared to the experimental one, the main difference is the relative absence of the $\mathrm{C}$ ideal orientation in Figure 2d. A second difference is the introduction of the rotated cube component of Figure $3 b$, which is responsible for the intensification of one of the two sets of $A / \bar{A}$ peaks in Figure $2 d$. These differences indicate that some 


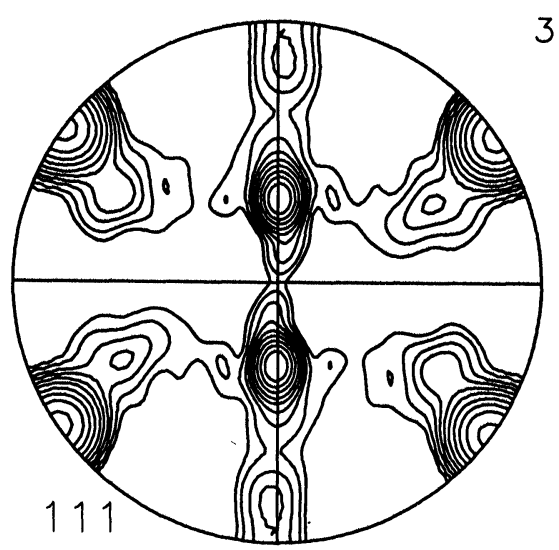

Figure 8 Simulated shear texture for the strain path corresponding to the $300^{\circ} \mathrm{C}$ test in Figure $1 \mathrm{a}$. Full constraints, rate sensitive slip with $\mathrm{m}=0.125$. Isovalues: $0.8,1.0,1.3,1.6,2.0,2.5,3.2,4.0,5.0$, 6.4 .

additional process (not only plastic slip) is contributing to the orientation change which leads to the disappearance of the $\mathrm{C}$ component. The most likely new mechanism that can appear in the present case is dynamic recrystallization.

The textures corresponding to room temperature and at $125^{\circ} \mathrm{C}$ are typical "high stored energy" textures. This is because of the predominance of the C component, which displays the highest Taylor factor among all the ideal orientations (1.73, Tóth et al., 1989). At higher temperatures, the texture shifts to progressively lower stored energies, as it is characterized by the $A / \bar{A}$, and $B / \bar{B}$ orientations, for which the Taylor factors are close to 1 , as well as by the cube $\left(\mathbf{M}=1.23\right.$ at $\left.\Phi_{1}=\pi / 4\right)$ and other low Taylor factor orientations. This means that grains in the $\mathbf{C}$ position are expected to undergo dynamic recrystallization earlier than those of any other ideal orientation (because they accumulate the highest dislocation densities during deformation). According to the oriented growth theory, those nuclei along the deformation fibre that are farthest from the $\mathrm{C}$ orientation (i.e. $B / \bar{B}$ and particularly $A / \bar{A}$ ) will grow the most quickly. These are in fact the main components of the modified texture that can be seen in the $300^{\circ} \mathrm{C}$ pole figure.

Thus the shortening behavior of heavily twisted copper bars appears to be a consequence of a dynamic recrystallization process that is initiated at elevated temperatures. Such a process leads to discrete grain reorientations that convert the orientation distribution from one in which the majority of the grains reside in the "lengthening" portions of the axial strain rate map (Tóth et al., 1990) to one in which most are located in the "shortening" regions. The characteristics of this reorientation process and its effect on the axial strain rate are beyond the scope of the present paper and will be presented in a separate publication (Tóth et al., 1992).

\section{CONCLUSIONS}

The length change measurements, supplemented by the pole figures and derived ODF's, have led to the following conclusions. 
1. When solid bar copper samples are twisted at a strain rate of $0.0038 \mathrm{sec}^{-1}$ to shear strains of $\gamma=11$, continuous lengthening is observed at room temperature and $125^{\circ} \mathrm{C}$. By contrast, at $200^{\circ} \mathrm{C}$ and $300^{\circ} \mathrm{C}$, there is lengthening to shear strains of about 10 and 5 , respectively, followed by shortening.

2. The pole figures of the room temperature and $125^{\circ} \mathrm{C}$ samples display the standard $\bar{A} / \overline{\mathrm{A}}, \mathrm{A}_{1}^{*}, \mathrm{~A}_{2}^{*}, \mathrm{~B} / \overline{\mathrm{B}}$ and $\mathrm{C}$ components normally observed during the ambient temperature shear deformation of fcc polycrystals. This type of texture development is readily simulated by the methods of rate sensitive crystal plasticity and is responsible for the lengthening behaviour.

3. The pole figures of the $200^{\circ} \mathrm{C}$ and $300^{\circ} \mathrm{C}$ samples indicate that, after a critical strain that decreases with temperature, the $\mathrm{C}$ component is progressively weakened and replaced by other components.

4. Analysis of the ODF's derived from the pole figures reveals that dynamic recrystallization leads to the introduction of a fairly stationary rotated cube component, as well as to the marked strengthening of the $A / \bar{A}$ orientation. The rotated cube component, together with some of the other rotated textures, is responsible for the changeover from "lengthening" to "shortening" behaviour.

\section{ACKNOWLEDGEMENTS}

The authors are indebted to Prof. P. Van Houtte for the use of his ODF calculation software. JJJ and LST are grateful to the Canadian Steel Industry Research Association and the Natural Sciences and Engineering Research Council of Canada for the partial support of this work.

\section{References}

Bailey, J. A., Haas, S. L. and Nawab, K. C. (1972). Journal of Basic Engineering, March, 231-237. Canova, G. R., Kocks, U. F. and Tomé, C. N. (1985). J. Mech. Phys. Solids, 33, 371-397.

Gilormini, P., Tóth, L. S. and Jonas, J. J. (1990). Proc. Roy. Soc. Lond., 430, 489-507.

Gil-Sevillano, J., Van Houtte, P. and Aernoudt, E. (1975). Z. Metallkunde, 66, 367-373.

Hardwick, D. and Tegart, W. J. McG. (1961). Mem. scient. Revue Metall., 58, 869-880.

Harren, S., Lowe, T. C., Asaro, R. J. and Needleman, A. (1989). Proc. Roy. Soc. Lond. A. 328, 443-500.

Montheillet, F., Cohen, M. and Jonas, J. J. (1984). Acta Metall., 32, 2077-2089.

Montheillet, F, Gilormini, P. and Jonas, J. J. (1985). Acta Metall., 33, 705-717.

Morozumi, F. (1965). Nippon Kokan Techn., Rep. no. 4, 67.

Neale, K. W., Tóth, L. S. and Jonas, J. J.(1990). Int. J. Plasticity. 6, 45-61.

Sekine, K., Van Houtte, P., Gil Sevillano, J. and Aernoudt, E. (1981). ICOTOM6, Ed. S. Nagashima, Tokyo, Japan, ISIJ p. 396-407.

Stüwe, H. P. and Turck, H. (1964). Z. Metallkunde, 55, 699-703.

Swift, H. W. (1947). Engineering, 163, 253-257.

Tóth, L. S., Gilormini, P. and Jonas, J. J. (1988). Acta Metall., 36, 3077-3091.

Tóth, L. S. and Jonas, J. J. (1989). Textures and Microstructures. 10, 195-209.

Tóth, L. S., Jonas, J. J., Gilormini, P. and Bacroix, B. (1990). Int. J. Plasticity. 6, 83-108.

Tóth, L. S., Jonas, J. J. and Van Houtte, P. (1992). To be published.

Tóth, L. S., Neale, K. W. and Jonas, J. J. (1989). Acta Metall., 37, 2197-2210.

Tóth, L. S., Szászvári, P., Kovács, I. and Jonas, J. J. (1991a). Textures and Microstructures, Vol. 14-18, ICOTOM 9 Special Issue, Guest Editors R. Penelle and C. Esling, pp. 995-1000.

Tóth, L. S., Szászvári, P., Kovács, I. and Jonas, J. J. (1991b). Materials Science and Technology. 7, 458-464.

Tóth, L. S. and Van Houtte, P. (1992). Textures and Microstructures, in press.

Van Houtte, P. (1991). Textures and Microstructures. 13, 199-212. 